\title{
Culture And Pragmatism
}

\section{The 8th EPS General Conference}

\author{
Amsterdam, 4-7 September 1990
}

The RAI Congrescentrum, site of the Society's 8th General Conference from 4-8 September 1990 and located just outside Amsterdam's old town, offered almost everything a conference could hope for.

The main auditorium was sumptuous and more than adequate for the 1000 participants. There was plenty of space in the hall outside, with its scattered tables and a $2 \pi$ array of commercial stands, for those essential informal get-togethers with colleagues. The restaurants ranged from the magnificent to the good value and the bars seemed to have an infinite half-life. Comfortable auditoria for the 16 parallel symposia and special sessions were close at hand, equipped with all the necessary and perfectly functioning apparatus. And there was plenty of room on the upper floor for handling some 300 posters over three days.

A more relaxed atmosphere might have been welcome but then the RAl is a commercial conference centre. Moreover, it has the advantage of being completely folded into Amsterdam's public transport system so participants could easily disperse to a wide variety of hotels, hostels and colourful cafes.

\section{PROGRAMME}

The conference was hosted by the Netherlands' Physical Society and the Local Organizing Committee chaired by the NPS Secretary, Professor A.M. Hoogenboom, had worked hard to ensure there was something for everyone.

Registrants on the Monday evening were treated to drinks and snacks at an informal get together in the RAI. Tuesday evening's official reception in the Rijksmuseum took place in the presence of Rembrandt's spectacular paintings. It was preceded by simulating talks to an invited audience at an opening session on aspects of science policy in the east and west (p. 173). The was a strong feeling that out of the synthesis of western pragmatism and eastern cultural values would emerge a stronger, richer physics community - a theme that set the tone for the conference with its 300 participants from the east. This is a a record number for a General Conference, testifying to the organizers' skills and effectiveness, and to the EPS's ability to bring east and west together.

An excellent rock group played to 150 at the Young People's Party held the following night at the Sleep in, which was the home for many younger participants in spite of some problems with micocreatures in bedding. On Friday afternoon, participants were bused directly from their excursions to an Open House at the Watergraafsmeer Science Centre where they were fêted to a percussion concert with cello accompaniment played on ... an accelerator. There was more traditional music to accompany smoked herring and a laptop dinner following an opportunity to visit the MEA accelerator complex, a particle detector display and exhibits by DESY and CERN that had been formally opened earlier in the week by Prince Claus of The Netherlands.

All this activity meshed in with a busy programme of plenary sessions (page 164) mainly in the mornings, and parallel symposia (page 168) in the afternoons. Spirits were still high at the closing ceremony with its speech by the EPS President, Professor R.A. Ricci (page 174), on Saturday afternoon. Nevertheless, we came home with the feeling that much had been achieved, at both technical sessions and meetings, in stimulating a blend of cultural values and pragmatic science.

\section{Profiting From Détente}

In hindsight, EPS may have been "a little ahead of its time". The Society was founded with a dream and it never wanted to give up its autonomy. And yet it was able to make important contributions by ensuring that there was "never a cold war in physics". Détente has now come - as the 300 participants from the east to EPS- 8 testify and EPS can justly claim some credit.

It was in about so many words that H.B.G. Casimir, the Society's third President, summed up in his inimitable style the new ambiance of European physics that should allow a marriage of the pragmatic and cultural views of research. His remarks followed the official opening by $\mathrm{H}$. de Waard, Chairman of the International Programme Committee, and his unhappy task of calling for a one minute silence in memory of Léon Van Hove who died the preceding weekend (appreciation on page 178).
Professor Casimir emphasized that general meetings help one to profit from different approaches by bringing physicists and branches of physics together on common ground. This is nowadays a challenge as the scope is vast, ranging from abstract mathematical theory to technical applications. Each physicist must usually find a niche as it is now simply impossible to be both a generalist and a pioneer.

Those with both views of research are naturally interested in the scientific trends. In offering a perspicacious personal opinion, Professor Casimir thought that high energy physicists will continue to "stir the vacuum with amazing tools". That the strict boundary between atomic theory and condensed matter will disappear as we learn to probe and manipulate matter on a scale ranging from the wavelength of light to the size of an atom. That quan-

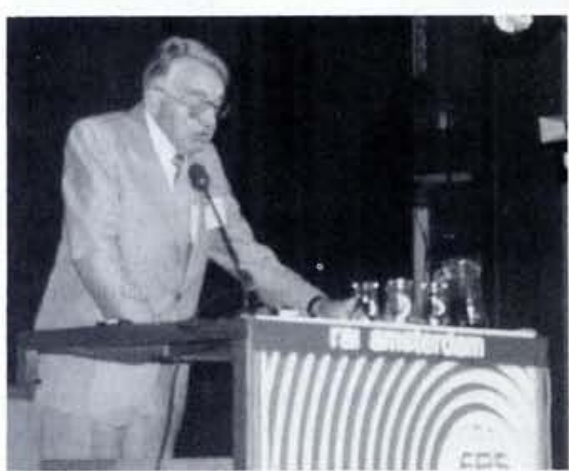

H.B.G. Casimir speaking at the EPS-8 opening ceremony.

tum mechanics will continue to penetrate the macroscopic world as can be seen in work on chaos and the curious behaviour in quantized systems. That research on field theory and elementary particles will not bring forth all the answers.

Clearly, physicists have much to learn, trends to follow and a spirit of reconciliation to help invigorate all those involved, young researchers especially. 